\title{
DETERMINISMO, FATALISMO, NECESIDAD: CICERÓN CONTRA LOS ESTOICOS
}

SALVADOR MAS

UNED

\begin{abstract}
RESUMEN: En la primera parte del presente artículo examino las categorías lógico-epistemológicas con las que Cicerón analiza el problema del determinismo, en particular al hilo de la distinción entre necesidad causal y lógico-epistemológica. En este contexto es fundamental el problema de la adivinación, esto es, la posibilidad de proferir enunciados verdaderos referidos al futuro, lo cual sugiere -como intento argumentar en la segunda parte- que, aunque sumamente técnica, la discusión de fondo no es lógico-epistemológica, ya que está en juego un problema religioso, esto es, político-religioso. Siguiendo a Carnéades, Cicerón critica de forma directa la epistemología estoica (en particular en la versión de Crisipo), pero porque indirectamente, y al margen del filósofo escéptico, desear superar las implicaciones teológicas de la concepción estoica del destino, lo cual, a su vez, es fundamental en su proyecto político de reconstrucción de la res publica: lógica, religión y política se dan la mano.
\end{abstract}

PALABRAS CLAVE: libertad, necesidad, determinismo, adivinación, Cicerón, Carnéades, Crisipo.

\section{Determinism, fatalism, neccesity: Cicero against the Stoics}

ABSTRACT: In the first part of this paper, I analyze the logical-epistemological categories that Cicero uses to address the problem of determinism, and in particular, the distinction between causal and logical-epistemological necessity. In this context, the problem of divination, that is, the ability to utter true statements about the future, is fundamental for Cicero, which suggests - as I argue in the second part of this paper - that Ciciero's substantive argument, albeit highly technical, in essence is not logicalepistemological, since what is fundamentally at issue is a religious, or political-religious, problem. Following Carneades, Cicero directly criticizes Stoic epistemology (in particular Chrysippus's version), but he does so because, indirectly, and independent of the skeptical philosopher, Cicero wants to overcome the theological implications of the Stoic concept of fate, which, in turn, is central to his political project for the reconstruction of the res publica: logic, religion and politics thus go hand in hand.

KEY WORDS: freedom, necessity, determinism, divination, Cicero, Carneades, Chrysippus.

Antes de entrar en materia conviene realizar alguna precisión conceptual y terminológica, pues debe distinguirse entre determinismo causal y determinismo lógico-epistemológico (Schallenberg, 2008, 4-6; O’Keefe, 2005, 10-14). Quienes defienden el primero conceden validez universal e irrestricta al principio de causalidad: nada acontece que no tenga una causa. Si es así, si todo lo que sucede es causado, todos los acontecimientos, incluidas las acciones y las decisiones humanas, formarán parte de una cadena que se remite infinitamente al pasado y que apunta, también infinitamente, al futuro. Tal cadena determina todo suceso de manera necesaria y no hay espacio alguno para la libertad, arrollada ante un fatum omniabarcador. Así parece desprenderse de las dos definiciones crisipeas de destino (SVF II, 913 y 100) que al hacerlo sinónimo de causalidad plantean con toda crudeza la alternativa o bien destino o bien libre albedrío. Cicerón, que transmite la noticia, puntualiza que con la palabra fatum indica lo que los griegos llamaban heimarménê y explica esta palabra como ordo seriesque causarum (De div. I, 125 = SVF II, 921).

El determinismo lógico toma pie en un concepto fuerte de verdad según el cual todos los enunciados son o bien verdaderos o bien falsos. El problema surge a propósito de las 
proposiciones referidas al futuro, cuyo valor de verdad se liga a una condición que, a su vez, depende de una concepción del tiempo en la que coincidían peripatéticos, estoicos y epicúreos (Weidemann, 2002, 251-260), pues todos ellos, no así los escépticos, consideraban que el tiempo no representa una ordenación (táxis) lineal de acontecimientos, sino un movimiento del cosmos, en virtud del cual cada estado del mundo se desarrolla a partir del precedente en la forma de un intervalo de movimiento (diástêma kinêseôs). De donde se sigue que existe (hypárchein), siempre y sólo, únicamente el presente, mientras que el pasado ya no existe y el futuro todavía no existe, sino que subsiste (hyphestánai) (Simplicio, In Arist. Cat. IX, 350, 14-16 = SVF II, 510 = 51A LS; Estobeo I, 8, 40 = SVF II, 509 = 51B LS; Plutarco, De comm. not. 1081 c - 1082 a = SVF II, 517, 518 y $519=51 \mathrm{C}$ LS). Si el futuro todavía no es real ahora, el acontecer de un suceso venidero no puede determinar ya en el presente la verdad o la falsedad de un enunciado referido a este suceso. Desde esta concepción del tiempo es plausible aceptar una condición de verdad para los enunciados referidos al futuro cuya satisfacción garantice, ya en el presente, la verdad de tales enunciados referidos al futuro. Lo dicho en el presente - así lo afirmarían los partidarios del determinismo lógico- fija las condiciones de verdad de los enunciados referidos al futuro.

En el origen de este planteamiento debe situarse en el famoso pasaje del De interpretatione aristotélico sobre «batalla naval»:

Digo, por ejemplo, que, necesariamente, mañana habrá o no habrá una batalla naval, pero no es necesario que mañana se produzca una batalla naval ni que sea necesario que no se produzca; sin embargo, es necesario que se produzca o no se produzca. De modo que, puesto que los enunciados son verdaderos de manera semejante a las cosas reales, es evidente que, en todas las cosas que se comportan de tal manera que pueden ser al azar cualquier cosa y lo contrario, la contradicción se ha de comportar de manera semejante; lo cual ocurre en las cosas que no siempre son o no siempre no son: de éstas, en efecto, necesariamente ha de ser verdadera o falsa una u otra parte de la contradicción, pero no precisamente ésta o ésa, sino cualquiera al azar, y puede ser verdadera una más bien que la otra, pero no verdadera o falsa ya. (18 b 30-35)

La necesidad — señala el Estagirita - se dice del enunciado completo, de la disyunción tomada en conjunto, no de uno de sus miembros por separado. Si es así, cabe que la disyunción de un enunciado y su negación sea verdadera sin que lo sean ni ese enunciado ni su negación: en tales casos rige el principio de tercero excluido pero no el de bivalencia. En el contexto de su crítica del determinismo, como premisa que conduciría a sentar que todo es por necesidad, o sea, en el contexto de una especie de reducción al absurdo, Aristóteles afirma que «necesariamente la afirmación o la negación ha de ser verdadera» (18 a 39 - b 2). Es probable que por detrás de estas consideraciones se encuentre el intento por responder a algunas versiones del «argumento ocioso» que tal vez circularan en círculos sofísticos o megáricos. En todo caso, y esto es lo que ahora interesa, en el mundo helenístico se vinculaba el principio de bivalencia y el determinismo (Kreter, 2006, 88-103; Rescher, 1963). Por eso los estoicos, defensores del fatum, reconocían este principio (De fato 38 = SVF II, 952), mientras que Epicuro, como Aristóteles y acaso por razones similares, no aceptaba que también las proposiciones referidas al futuro fueran o bien verdaderas o bien falsas (Cic., Acad. II, 97 = SVF II, 219).

Avergonzados de tal afirmación, dice Cicerón, los epicúreos sostuvieron algo todavía más vergonzoso: «que son verdaderas las disyunciones entre los contrarios, pero que, de los enunciados que hay en ellas, ni el uno es verdadero ni el otro falso» (De fato 36-37). Es vergonzosísimo, pues, admitir el principio de tercero excluido y limitar el de bivalencia, ya que en el marco de la lógica clásica ambos principios se exigen: admitir el uno obliga a aceptar el otro. Quizás el temor a las consecuencias deterministas que pudieran 
derivarse de la aceptación radical del principio de bivalencia condujo a Epicuro a cometer este grave error: " $¡ \mathrm{Oh}$ admirable licenciosidad y desdichada ignorancia en el arte de disertar!», escribe el Arpinate (De fato 36-38).

Aristóteles y Epicuro consideraban que los predicados «verdadero» y "falso» son aplicables a los enunciados en un momento determinado, o sea, con un alcance estrictamente temporal y según la concepción del tiempo esbozada más arriba; puede decirse, en efecto, «es ahora verdad que mañana habrá una batalla naval». Desde un punto de vista lógico este «ahora» es superfluo e introduce innecesarias complicaciones metafísicas en relación con el problema de la verdad (Kneale, 1972, 48-49), complicaciones, sin embargo, de las que epicúreos y estoicos ni podían ni querían escapar, pues para unos y otros el determinismo lógico-epistemológico y el causal se implican entre sí. Cicerón señala que Crisipo afirmaba que «no pueden ser verdaderas aquellas cosas referidas al futuro que no tienen una causa en virtud de la cual puedan llegar a producirse» (De fato 26), de donde se sigue que hay ahora alguna causa para predicar la verdad o la falsedad de los enunciados futuros, el fatum. Epicuro, por el contrario, temía que la verdad o la falsedad de los enunciados futuros, esto es, su más absoluta determinación, dependiera de «causas externas y que manan de la necesidad de la naturaleza». Por eso Crisipo probaba el determinismo causal a partir del principio de bivalencia argumentando que si hubiera algún movimiento sin causa ningún enunciado podría ser verdadero o falso, «porque aquello que no tiene causas eficientes, no será ni verdadero ni falso» (De fato 19-21 = SVF II, 952 y 954).

Las fuentes antiguas no distinguen con claridad entre el determinismo lógico y el epistemológico, aquél que afirma que hay quien sabe qué ocurrirá en el futuro. Esta forma de determinismo suele emplearse para ilustrar el lógico: aunque las proposiciones referidas al futuro sean desde siempre o verdaderas o falsas, los humanos lo ignoramos; sólo lo saben un dios o un adivino. A fin de cuentas, fatum es el participio perfecto pasivo sustantivado del verbo fari, que significa «decir» o "hablar»; literalmente traducido, fatum significa «lo dicho»: desde un punto de vista mítico-religioso, lo dicho por un dios o por un adivino que se encuentra en relación inmediata con la divinidad. Tal decir será necesariamente verdadero: lo que los dioses afirman sobre los individuos, las ciudades y los pueblos (el fatum que les decretan) habrá de cumplirse, y dado que los dioses de Roma acostumbran a decir destinos desgraciados se explica que entre los romanos el sustantivo fatum y el adjetivo fatalis tuvieran connotaciones negativas, cosa que no siempre sucede con la voz griega heimarméne. Cuando Platón sostiene que los hombres son marionetas de los dioses (Leyes 644 c y ss.) no afirma nada negativo, sino que conviene seguir el hilo áureo y sagrado de la razón: tal vez lo mejor para los humanos sea, en efecto, aceptar tal condición de títeres. Es de necios no plegarse al destino, querer modificar lo querido y dicho por la divinidad no indica libertad, sino una doble estupidez: la de la ignorancia, por no comprender la perfección y la necesidad de este fatum; y la de la arrogancia, por querer mejorarlo alterándolo (Vegetti, 1983, 32). Sólo el sabio no se engaña, sólo él acepta representar el papel que le ha sido dado, dirán los estoicos.

Carnéades y con él Cicerón aceptaban que el determinismo epistemológico implica el causal y el lógico, así como que el causal conlleva el lógico, pero sostenían que el determinismo lógico no supone ni el causal ni el epistemológico. Por eso defendían que los determinismos causal y epistemológico son falsos, mientras que el lógico es verdadero, si bien inocuo. Dicho de otra manera: Carnéades y Cicerón admitían de manera irrestricta el principio de bivalencia y la validez incondicionada en el ámbito natural del principio de causalidad, pero negaban que de aquí pudieran inferirse consecuencias 
fatalistas, porque la voluntad humana, por su propia naturaleza, siempre tiene la posibilidad de iniciar nuevas cadenas causales.

El determinista niega que podamos hacer cosas diferentes de las que hacemos, también rechaza la apertura o contingencia del futuro. Bien sea porque éste dependa de una concatenación causal necesaria, bien sea porque "ya está dicho», el determinismo plantea dos problemas de enorme importancia: el de la responsabilidad moral y el de la racionalidad de las deliberaciones y las acciones.

La caracterización del fatum que Quinto ofrece en Sobre la adivinación I, 125 (tras afirmar, con Posidonio, que «la razón nos obliga a reconocer que todo ocurre a consecuencia del destino») se corresponde casi por completo con la definición estoica del principio de causalidad (Duhot, 1989). De donde se infiere — continúa el hermano de Cicerón-que el destino no es lo que dice «la superstición», sino «la ciencia»: la causa eterna de todas las cosas «en virtud de la cual se produjo lo ya pasado, ocurre lo que está en ciernes y va a pasar lo que viene después». Si hay una providencia divina que quiere lo bueno (y la hay), el futuro estará determinado desde la eternidad y tiene que existir el destino (De div. I, 82 - 83). Por otra parte, todo lo que existe debe tener una causa. De aquí la definición estoica del destino como «serie imperecedera de causas» (De fato 20-21). Esta combinación de elementos teológicos, físicos y epistemológicos alumbraron determinismos tan rígidos como el defendido por Diodoro en el llamado «argumento dominante» (De fato, 13; tb. Epícteto, Diss. II, 19, 1-4) (Long, Sedley, 1990, 234-236). Pero antes de entrar en esta cuestión tal vez no sea impertinente realizar una breve consideración, más estrictamente lógica, acerca de la implicación, pues los enunciados referidos al futuro en los que se manifiesta la presencia del fatum acostumbran a presentarse como implicaciones.

Sexto Empírico señala que los antiguos entendían la implicación de cuatro maneras: la primera, más débil, la adscribe a Filón, la segunda a Diodoro, la tercera a Crisipo, la cuarta, la más fuerte, no la refiere a ningún grupo en particular, si bien cabe pensar que era defendida por los peripatéticos (Adv. Math. VIII, 112). De acuerdo con Filón una implicación es verdadera si no comienza con lo verdadero y finaliza con lo falso; para Diodoro una implicación es verdadera cuando ni es posible ni será posible que comience con lo verdadero y finalice con lo falso. Crisipo, por su parte, llama verdadera a una implicación cuando el opuesto contradictorio del consecuente es incompatible con el antecedente. Cabe entonces suponer que en los argumentos que Cicerón dirige contra Crisipo también se discute esta implicación estricta.

Sea la proposición «si uno ha nacido cuando sale la Canícula, ése no morirá en el mar»; si es verdadero lo indicado en ella, también lo será lo dicho en esta otra: «si Fabio ha nacido cuando sale la Canícula, Fabio no morirá en el mar». Por tanto, las proposiciones "que Fabio haya nacido cuando sale la Canícula» y "que Fabio vaya a morir en el mar» son contradictorias: no pueden ser verdaderas al mismo tiempo. Si es así, la proposición «que Fabio haya nacido cuando sale la Canícula y que Fabio vaya a morir en el mar» expresa una imposibilidad lógica: dada la primera es imposible que sea la segunda. A partir de aquí Cicerón concluye que cuanto se diga en falso con referencia al futuro, no puede llegar a ocurrir. Crisipo, en efecto, identifica los enunciados condicionales y los enunciados de implicación: interpreta el consecuente del condicional como algo que se sigue lógica (y causalmente) del antecedente. Aunque es evidente que si un enunciado implica a otro cabe construir un condicional verdadero en el que el primer enunciado funcione como antecedente y el segundo como consecuente, de aquí no se sigue que el antecedente de un condicional verdadero ( Fabio nació cuando salió la Canícula») implique siempre el consecuente («Fabio no morirá en el mar»). 
Debe reconocerse que no está nada claro qué quiere decir Cicerón: si una implicación se formula como un condicional verdadero en términos de prótesis (antecedente) y apódosis (consecuente), el antecedente implica, o de él se sigue, el consecuente; en tal caso, el siempre es, en el presente contexto, irrelevante o un mal sustituto de la consecuencia lógica. Pero acaso el Arpinate desee sugerir que si, pongamos por caso, $\mathrm{P}$ implica $\mathrm{Q}$ se formula como un condicional verdadero en el sentido de que necesariamente (o sea, siempre) «si $\mathrm{P}$, entonces $\mathrm{Q}$ », de ahí no se sigue que «si $\mathrm{P}$, entonces necesariamente $\mathrm{Q}$ ».

En todo caso, Cicerón no ha demostrado (ni lo pretende) la imposibilidad de formular proposiciones adivinatorias verdaderas, esto es, verdades futuras dichas a partir de verdades presentes, sino que el concepto de posibilidad de Crisipo es tan determinista como el de Diodoro, de acuerdo con el cual si fuera posible algo que no es ni en el presente ni en el futuro, lo imposible (que, por definición, ni es ni puede llegar a ser) surgiría o podría surgir a partir de lo posible. Si a partir de lo posible no puede surgir lo imposible, sólo es posible o bien lo que es en el presente o bien lo que será en el futuro. De donde se sigue que «posible» sólo es el nombre dado a nuestra ignorancia del futuro, pero que si tal insipiencia desapareciera, como le sucede al menos tendencialmente al sabio, habría que reconocer que todo ha sucedido, sucede y sucederá por necesidad, pace la teoría modal crisipea, que intenta mostrar —incurriendo en graves errores, según Cicerón-que aunque todo está predeterminado por el fatum, no todo lo que ocurrirá en el futuro es necesario, pues son posibles acontecimientos que no ocurrirán realmente.

Plutarco recuerda que Diodoro ofrecía la siguiente definición de "posible»: «aquello que o bien es verdad o bien lo será», de la que se siguen las consecuencias deterministas, incluso fatalistas, indicadas más arriba (Stoic. repug. 1055 e-1056d = SVF II, 202). Para escapar de ellas Crisipo ofreció esta otra definición: «todo cuanto es susceptible de suceder, aunque no vaya a suceder, es posible», a la cual llegó negando la segunda premisa del argumento dominante («de una proposición imposible no se sigue una proposición posible») y aceptando la primera («toda proposición pasada es necesaria») y la tercera («una proposición posible es aquélla que no es ni será verdadera»). Crisipo introduce posibilidades contrafácticas en la teoría estoica del fatum para poder defender que aunque se concrete una única posibilidad ello no quita para que existieran muchas, entre las cuales cabe, o cupo, elegir. Vano intento de acuerdo con Cicerón y Plutarco, el refinamiento modal introducido por Crisipo no alcanza a reducir el hecho, fundamental en la teoría estoica, de que la existencia del fatum implica la validez incondicionada del principio de causalidad. Por eso dice Plutarco que la doctrina de la posibilidad crisipea se contradice con su doctrina del fatum: si se acepta aquélla, éste pierde "su fuerza insuperable, ineluctable y omnipotente», cosa que Crisipo en modo alguno aceptaría.

Si los acontecimientos futuros están producidos por una cadena causal que se despliega necesariamente, en tal caso, los mismos motivos que hacen necesario a un acontecimiento hacen imposible a su opuesto contradictorio; de donde sigue que la aceptación, indispensable desde las presuposiciones estoicas, de tal cadena causal omniabarcadora es condición suficiente y necesaria para eliminar cualquier posibilidad contrafáctica (Alejandro de Afrodisia, De fato X, 176, 14-24 = SVF II, 959). En Sobre la adivinación I, 127 (= SVF II, 959), asumiendo posiciones estoicas, Cicerón compara el paso del tiempo con el despliegue de un cable: lo que sucederá no acontece de pronto, va desarrollándose poco a poco a partir de lo pasado en función de una Providencia divina que rige el mundo apuntando siempre a lo mejor: no cabe aceptar a la vez las posibilidades contrafácticas y la prónoia divina, a menos de admitir que nos encontramos ante una de esas paradojas que sobrepasan la capacidad de comprensión humana: repugnantiae o paradoxa stoicorum, como las llamaban sus oponentes. 
Con respecto al «argumento dominante» —explica Cicerón-Crisipo, «para no coincidir con Diodoro, enseña a los caldeos cómo conviene que expongan sus saberes» (De fat. 15). Al margen de la ironía, el Arpinate apunta a un problema serio. Los caldeos y los estoicos con tendencias fatalistas se aprovecharon de que la actividad cognoscitiva inferencial de los humanos descansa en la disposición hermenéutica natural de considerar unas cosas como signos de otras: los sentidos, afirma el estoico Balbo, "son intérpretes y anunciadores de las cosas» (De nat. deor. II, 140), lo cual, a su vez, conduce a formular condicionales cuyo antecedente funge como signo del consecuente, convirtiendo a su vez los nexos proposicionales en nexos causales (Vega Reñon, 1990, 244-245). Tal era la crítica que Carnéades dirigía a Crisipo, a saber, que confundía necesidad lógica y física, distinción ésta, sin embargo, imposible de realizar desde supuestos estoicos, que estipulan que verdad, causa, naturaleza, necesidad y razón (lógos) sólo son aspectos parciales y complementarios de un Lógos cósmico, universal y omniabarcador, como dice la ya citada definición de SVF II, 913. Por ejemplo: si hay partes del cuerpo «sumamente aptas para procrear y para concebir» y si «son admirables en macho y hembra los deseos que tienen de acoplar sus cuerpos», entonces - como consecuencia no sólo lógica, sino causal - hay «una naturaleza proveedora y diestra» (De nat. deor. II, 128); otro ejemplo: "si has nacido al salir la Canícula no morirás en el mar», la forma que, acuciado por el fantasma del fatalismo, Crisipo autoriza a médicos y geómetras, pero prohíbe a los adivinos, los cuales deberían decir más bien «No: alguien ha nacido al salir la Canícula y morirá en el mar», como si — tal es la ironía ciceroniana- la sustitución de los condicionales por composiciones conjuntivas solucionara el problema, central en el planteamiento crisipeo, de rechazar la necesidad aceptando a la vez que nada sucede sin que existan causas preestablecidas. Crisipo, sin embargo, tenía buenas razones para proceder de esta manera: la existencia del fatum expresa una causalidad que actúa eterna e ilimitadamente en el mundo, no una superstición astrológica de acuerdo con la cual las estrellas tienen un influjo necesario en el transcurso de las cosas y las acciones (Schallenberg, 2008, 150 ss.).

Recogiendo argumentos estoicos a favor de la adivinación, Quinto argumenta que las constelaciones astrales deben entenderse como signos, como un don que los dioses ofrecen a los mortales para que seamos cautos y hagamos el bien (De divin. I, 82-83 = SVF II, 1192). Como todos los acontecimientos, los signos integran el nexo causal cósmico, por lo que su aparición y corrección se fundamenta en la sympátheia universal. Un signo remite a un acontecimiento, pero no está en relación causal directa con él. Por tanto, no hay ligazón necesaria entre el signo mántico y el acontecimiento por él profetizado. Crisipo, en definitiva, ya lo sugería más arriba, no niega la corrección de las proposiciones adivinatorias, pero considera inadecuado presentarlas bajo la forma de composiciones conjuntivas. Son o pueden ser fácticamente correctas, no con necesidad, porque no existe ninguna conexión fundamentada por leyes lógicas o físicas entre el antecedente y el consecuente de la implicación. Desde este punto de vista, el cambio en la forma de expresión sugerido por Crisipo no es, o no es sólo, como dice Cicerón, «una graciosa arbitrariedad» (De fato, 12-16), sino un refinamiento de las estrategias para expresar diferenciaciones lógico-modales.

Aunque se acepte que es así, y aunque se admita que trabajar a partir de paradojas era un método estoico (Cic., Stoic. parad. praef. 4), cabe preguntarse qué ha ganado de esta manera Crisipo en relación con la discusión sobre el fatum. Y la respuesta es nada: dada una descripción completa del mundo, y sobre la base de la validez universal del principio de causalidad así como de ese concepto de verdad fuerte que afirma que todas los proposiciones son o bien verdaderas o bien falsas, bajo tales condiciones, existen 
en el presente o bien causas para que Fabio muera ahogado en el mar o bien para que no muera de esta manera. Si lo primero, Fabio morirá ahogado necesariamente, si lo segundo no fallecerá entre las olas, de manera asimismo necesaria, al margen de que la proposición que enuncia uno u otro hecho se exprese de esta o aquella manera.

Que Crisipo era consciente de las dificultades de su posición lo muestra el hecho de que dedicara enormes esfuerzos a intentar combatir el llamado "argumento ocioso», de acuerdo con el cual, caso de obedecerlo, escribe Cicerón, «no haríamos en la vida absolutamente nada»: de nada vale recurrir al médico, pues si el destino es que te cures te curarás y si el destino es que no te cures no sanarás, aunque vayas al médico ( $D e$ fat. 28-30; Orígenes, Contra Celsum = SVF II, 957). El fatalismo defendido por algunos estoicos conduce a la absurda consecuencia de la inutilidad de cualquier pensar, planear y actuar, de manera que el hombre quedaría condenado a la inactividad. Crisipo intentó rebatir este argumento distinguiendo entre acontecimientos simples y complejos ( $D e$ fato 30 = SVF II, 956).

Como ejemplo de acontecimiento simple Cicerón propone: «Sócrates morirá tal día». Esta proposición se malinterpretaría si se creyese que se limita a enunciar que, dado que Sócrates es humano, y ya que todos los hombres somos mortales, Sócrates habrá de morir, pues, como ha sugerido Sedley (1992, 316 ss.), el ejemplo debe entenderse desde el sueño premonitorio de Sócrates que Platón recoge en Critón 44a, sueño que - desde una perspectiva estoica - le hace saber que su determinación es morir determinado día: Sócrates sigue por su propia voluntad lo que el dios ha dispuesto para él y le ha hecho saber mientras dormía. Acontecimientos complejos serían «Edipo nacerá de Layo» y "Milón luchará en los juegos de Olimpia»: difícilmente nacerá Edipo de Layo a menos que este mantenga relaciones sexuales con una mujer, y difícilmente competirá Milón en los juegos Olímpicos a menos que tenga adversario. No es «ocioso» que Layo mantenga o no mantenga relaciones sexuales, ni que Milón tenga o deje de tener un adversario. En general: si un acontecimiento A («Edipo nacerá») está relacionado con un acontecimiento B ( $L$ Layo engendra») y si A está determinado por el fatum, entonces $\mathrm{B}$ deberá acontecer por necesidad junto con A, dado que su acontecer está codeterminado por el destino; Crisipo denomina a esta circunstancia «destino compartido» (confatale). En tales casos, de que A esté determinado por el fatum no puede concluirse que A acontecerá al margen de que B también acontezca o no: ciertas consecuencias, aunque necesarias, no pueden producirse si no concurren algunas acciones humanas que, en consecuencia, decía, no pueden calificarse de «ociosas». Cabe que la posición de Crisipo sea determinista, pero no es fatalista en sentido estricto, al menos en su propia autocomprensión.

A la altura de Sobre el destino 39-45 (= SVF II, 974) Cicerón distingue dos grupos de filósofos: los que sostienen que todo sucede a consecuencia del destino y los que consideran que existen movimientos voluntarios del espíritu «sin que intervenga destino alguno», y afirma que Crisipo intentó ocupar, sin lograrlo, un lugar intermedio. Crisipo - pensador sutilísimo donde los haya- sugiere distinguir entre causas determinantes y causas preliminares, con las palabras de Cicerón: causas «absolutas y principales» (perfectae et principales) y causas "coadyuvantes y secundarias» (adiuvantes et proximae) (De fat. 39-45). Si bien el estímulo externo es causa necesaria para que algo se produzca, no lo produce necesariamente: aunque es causa preliminar, lo que determina la acción y es, en consecuencia, causa «absoluta y principal», es el asentimiento (adsensio) que el sujeto da o no da a tal estímulo inicial. El asentimiento no puede producirse sin una fuerza procedente del exterior, pero una vez que tal fuerza ha actuado la acción no está motivada de manera fatalista por ella, sino determinada por la forma de ser o la índole 
moral del sujeto que asiente o deja de asentir, al igual que quien empuja un cilindro por una rampa le da el principio motriz, no el movimiento rotatorio que constituye su forma específica de moverse. Entramos de este modo en la teoría estoica de la acción.

Para los estoicos, la realización de una acción comienza con una representación (phantasía, visum) que a su vez, en un segundo momento, es sometida a prueba por la razón en orden a determinar si lo representado es bueno y digno de llevarse a cabo. Si la evaluación es positiva, acontece el asentimiento (sunkatáthesis, adsensio) que, a su vez, produce un impulso (ormê, adpetitus): el movimiento del alma hacia algo o alejándose de algo (SVF III, 169; SVF III, 377). De acuerdo con Crisipo, este movimiento es el fundamento racional que ordena actuar a los individuos (Plutarco, Stoic. repug. 1037 $\mathrm{f}=$ SVF III, 175). En Epístola moral a Lucilio 113, 18 (= SVF III, 169.1) Séneca habla de un impulso irracional previo al asentimiento, pero para Crisipo — que en este punto representa la ortodoxia estoica - tal impulso es racional, sigue al asentimiento que es, igualmente, racional: cuando este impulso es llevado a cabo, se realiza la acción representada; esquemáticamente: representación $\rightarrow$ asentimiento $\rightarrow$ impulso $\rightarrow$ acción. Esta división sólo tiene sentido analítico, pues en realidad estamos ante un proceso unitario, dado que la representación, el asentimiento y el impulso representan distintas capacidades de la parte directiva del alma (hêgemonikón); y en esta unidad se manifiesta la racionalidad de las acciones humanas. Los animales también poseen impulsos, pero no racionales, ya que reaccionan inmediata y necesariamente ante las representaciones: entre la representación y la acción falta el asentimiento (Alejandro de Afrodisia, De fato XIV, 183-184 = SVF II, 981; Orígenes, De principiis III, 1, 2-3 = SVF II, 988). El ejemplo del cilindro muestra que para un individuo, bajo las mismas condiciones, debe ser posible asentir o no asentir a una representación, y a este respecto es fundamental diferenciar causas.

La representación externa es causa precedente que, en tanto que tal, se limita a iniciar el proceso de asentimiento, pero en modo alguno lo efectúa con necesidad; la responsabilidad fundamental de tal asentimiento, repito, debe buscarse en el carácter individual de los sujetos. O lo que es lo mismo, el fatum no actúa sobre la acción directamente por medio de la representación, sino indirectamente a través del carácter, en cuya formación intervienen múltiples factores. El hombre es actor de sus acciones y no puede hacerse al fatum responsable directo de ellas; tal responsabilidad depende, insisto, del carácter entendido como una causa interna no precedente que ni obliga ni impide con necesidad, como muestra o visualiza el ejemplo del cilindro, el cual rueda como rueda porque tiene forma cilíndrica: ninguna fuerza externa obliga al cilindro a rodar como cilindro, sino porque está en su naturaleza de cilindro el rodar como cilindro. Por tanto, lo que acontece en función de la naturaleza propia e individual (katà tên oikeían phýsin) acontece por necesidad (katênankasménos), pero no forzosamente (ék bías) (Alejandro de Afrodisia, De fato XIII, 181-182 = SVF II, 979). De nuevo la teoría modal estoica permite trazar una distinción que Cicerón considera verbal: necessitas, para él, traduce tanto anánkê como bía (Wicke-Reuter, 2000, 45). Tal vez si el Arpinate hubiera mantenido la distinción terminológica estoica y hubiera vertido anánke por necessitas y bía por vis habría sido al menos sensible a los esfuerzos crisipeos por aproximar dos posiciones que, debe reconocerse, no son fáciles de reconciliar. Pero los intereses ciceronianos, como habrá que ver más adelante, apuntan en otra dirección: por eso considera que Crisipo y los fatalistas coinciden y que sólo de palabra puede el primero distinguir entre la concepción determinista estoica tradicional y una pluralidad de causas que, se supone, le permite concebir el asentimiento como factor causalmente relevante, pero no determinante de manera necesaria. La admisión radical de la libertad obliga a negar 
con no menor radicalidad el destino, tanto da concebido como causa preliminar o como causa determinante.

En De fato 39-45 Cicerón distingue dos grupos de defensores de la libertad: los primeros niegan que el asentimiento sea consecuencia del fatum y afirman que ocurre gracias a una representación previa; los segundos niegan que el asentimiento sea consecuencia del fatum, pero, a diferencia de los primeros, coinciden con Crisipo en afirmar que todo acontece mediante causas precedentes. De esta concesión no se sigue que todo acontezca por necesidad, porque la representación (en tanto que causa precedente para que tenga lugar un asentimiento) es tan sólo una causa no necesaria para que tenga lugar el asentimiento: de que todo acaezca en virtud de causas precedentes no se sigue que todo lo haga en virtud del fatum. Crisipo, por su parte, afirma la existencia del fatum, de donde se sigue que todo acontece en virtud de causas precedentes, pero no que todo acontezca con necesidad: en virtud de la diferenciación de causas a la que me refería más arriba hay causas que no producen con necesidad su efecto. Tal es el caso de la representación que, ciertamente, produce un asentimiento, pero no con necesidad, como sostenían los segundos defensores de la libertad.

Crisipo y estos defensores de la libertad convienen en afirmar la existencia de causas precedentes cuyos efectos no está en nuestra mano evitar, tales serían las causae perfectae et principalis; pero coinciden asimismo en que también hay otras causas precedentes, las causae adyuvantes et proximae, cuyos efectos sí podemos controlar: está en nuestra mano el desarrollo de los acontecimientos, esto es, influir en los acontecimientos subsiguientes. La única diferencia es la concepción de fatum: Crisipo acepta una versión débil (con implicación de necesidad), los defensores de la libertad rechazan una noción fuerte (sin implicación de necesidad). Cicerón afirma que «se encuentran distantes en las palabras y no en lo esencial» (De fato 39-45), pues mientras que los segundos defensores de la libertad sólo hablan de fatum en aquellos casos en los que las causas producen su efecto con necesidad, Crisipo también utiliza esta palabra cuando hay factores causales que representan condiciones necesarias pero que no obran con necesidad: la condición cilíndrica de un cilindro es condición necesaria para que un cilindro ruede como ruedan los cilindros, pero en modo alguno es necesario que un cilindro tenga que rodar. Para que esto último suceda tiene que intervenir otra causa, por ejemplo, que alguien lo empuje; y que alguien lo empuje es, a su vez, condición necesaria para que el cilindro ruede, mas debe reconocerse que en modo alguno es necesario que alguien empuje un cilindro, para que esto suceda debe intervenir otra causa, pongamos el deseo de desplazarlo. Y para que un cilindro se desplace es, desde luego, condición necesaria el deseo de desplazarlo, mas sigue sin ser ineludible este deseo de mover el cilindro, lo cual exigiría otra tercera causa y ésta una cuarta y así sucesivamente... Crisipo mantiene la idea de una cadena causal infinita, irrenunciable desde premisas estoicas, pero, por así decirlo, la desfigura, para de este modo dar cabida a algún tipo de responsabilidad moral. Cicerón, por su parte, exige con mayor radicalidad la posibilidad de iniciar cadenas causales del todo inéditas, posibilidad que argumentará tomando pie en la idea de Carnéades de la voluntad como causa por entero diferente de las que rigen en la naturaleza.

Todo depende de qué se considere irrenunciable, de dónde se sitúe el acento. Los estoicos lo ponen en la existencia de una Providencia divina que siempre y en todas partes quiere lo bueno y a partir de aquí intentan, si se me permite expresarlo así, salir del apuro. En este proceso de superar dificultades, aunque no se consiga vencerlas del todo, se alcanzan al menos perspectivas interesantes: en el caso de la Stoa, decisivos avances y refinamientos en el ámbito de la lógica modal. Y si estos avances no interesan o se consideran irrelevantes es que, a fin de cuentas, interesan otras cosas y se pone el 
acento en otro lado, como hace Cicerón siguiendo a Carnéades y como habrá que ver en las páginas siguientes.

Para escapar del caos y del azar, para afirmar la existencia de una prónoia, los estoicos defienden una estrecha línea de continuidad entre teología, adivinación y destino, que los epicúreos niegan. Cicerón considera inaceptables ambas posiciones: el carácter político de la religión romana obliga tanto a admitir la intervención de los dioses como a negar las tesis epicúreas que, en el fondo, constituyen una forma solapada de ateísmo. Epicuro sólo puede eliminar la adivinación al precio de suprimir indirectamente a los dioses. Este planteamiento obliga a entrar en la cuestión de la superstición, pues en ella, aunque de manera viciosa, se manifiesta una religiosidad más allá del mero ritualismo contractual. Para liberarse de la superstición, del vano temor a los dioses, Cicerón propone el estudio de la naturaleza, que exige determinar con precisión el principio de causalidad, de tal forma que sea compatible con la intervención de los dioses en el mundo (patente sobre todo en situaciones de grave peligro para la República), pero sin caer ni en la temerosa superstición ni en el determinismo fatalista.

De aquí la importancia fundamental de la teología para la vida práctica, no porque el discurso y la investigación sobre los dioses sean fuente y fundamento de la moral y de la correcta ordenación de los asuntos públicos, pero sí para la conformación de una religión positiva con buena visibilidad política. En este contexto es esencial el problema de si los dioses se cuidan o no del mundo y de los hombres y hasta qué punto lo hacen, esto es, debe investigarse la cuestión que nos ha ocupado en las páginas precedentes, la relación entre fatum y libertad subjetiva de acción y deseo, pero superando tanto la azarosidad epicúrea, cuanto el concepto estoico de causalidad, que obliga a un determinismo extremo, del todo incompatible con esa primacía de la conciencia moral que ya comienza a insinuarse en estos textos ciceronianos y que, decía, exige libertad.

Junto con la pietas, la sanctitas y la religio, el cuarto factum de la reflexión teológica ciceroniana es la libertad: la acción intencional humana libre es un hecho de experiencia. A modo de indemostrable punto de partida, como axioma de su concepción religiosa, Cicerón parte de que existe la libertad personal al margen de cualquier concatenación causal necesaria. Criticando las teorías posidoniana y crisipea de la sympátheia, señala que no duda de que existan causas naturales antecedentes, tampoco que en virtud de ellas cada cual sea propenso a unas cosas, pero inclinación no es determinación (De fat. 8-9).

En Sobre el destino 5-10, discutiendo las tesis de Posidonio y Crisipo sobre la influencia causal que los estímulos externos ejercen sobre el cuerpo y el alma de los humanos (naturae contagio), Cicerón acepta que las causas naturales influyen sobre la propensio pero no sobre nostrae voluntates atque adpetitiones. La naturaleza del alma es moverse a sí misma; sus movimientos voluntarios no tienen una causa externa, pero tampoco son incausados, "porque la causa de esta circunstancia es su propia naturaleza»: no es que el alma sea libre por naturaleza, es que la naturaleza del alma es «estar bajo nuestra potestad y obedecernos», como decía Carnéades criticando las tesis epicúreas (De fat. 25). Es, pues, el momento de intentar precisar las tesis del filósofo académico.

Carnéades acepta el principio de bivalencia sin ningún tipo de restricciones ( $D e$ fato 36-38), pero niega que de él se sigan consecuencias deterministas, ya que la verdad de un enunciado no implica que existan causas eternas e inmutables que lo hagan verdadero. El determinismo lógico no supone el causal, porque, a diferencia de la concepción 
temporal defendida por estoicos y epicúreos, Carnéades introduce una asimetría esencial entre pasado y futuro: así como el hecho de que algo fuera verdadero en el pasado no depende de que tenga consecuencias ahora, algo que será verdadero en el futuro no depende de que tenga ciertas causas ahora: llamamos verdaderas a aquellas proposiciones pasadas cuyo advenimiento se verificó en el pasado y, de igual modo, "hemos de llamar verdaderas a aquellas cosas cuyo advenimiento se verificará en un tiempo futuro" (De fato 27-28).

En el mundo físico-empírico rige de manera incondicionada la causalidad natural, de suerte que también las disposiciones caracterológicas de los seres humanos estarán determinadas por un conjunto de causas precedentes. Pero de aquí Carnéades no concluye que los actos de voluntad también estén determinados por causas precedentes. Es cierto que hay paralelismos («simpatías») entre la naturaleza de los lugares y el carácter de los individuos, de suerte que la atmósfera ligera del Ática hace que los atenienses sean agudos, mientras que la más densa de Tebas hace a los tebanos toscos y vigorosos. «Sin embargo — argumenta Cicerón en la línea de Carnéades-, ni aquella atmósfera ligera hará que uno escuche a Zenón, a Arcesilao o a Teofrasto, ni la densa le hará buscar la victoria de Nemea más que la del Istmo» (De fato 7 = SVF II, 950). O sea, la voluntad puede imponerse sobre las disposiciones del carácter y, en esta medida, sobre la causalidad natural. Por esto Carnéades y Cicerón veían innecesaria la concesión indeterminista de la física epicúrea, porque consideraban que junto con las causas externas y precedentes, los actos de voluntad implican una causalidad diferente que surge con la misma voluntad y que, en consecuencia, siempre cabe la posibilidad de iniciar series causales nuevas. Los actos de voluntad no son incausados (como el clinamen epicúreo), pero tampoco forman parte de una cadena causal, por muy desfigurada que esté, que se remonta y remite al infinito (como se veían obligados a sostener los estoicos): la causa de un acto de voluntad reside en la naturaleza de la misma voluntad. De aquí que Carnéades niegue también el determinismo epistemológico: ni tan siquiera «habría podido Apolo hacer predicciones acerca de Edipo» (De fato 33), sólo podría haberlas realizado si hubieran existido causas preestablecidas naturales que determinaran sus acciones. Tales causas no existen, lo cual no quiere decir que las acciones de Edipo sean incausadas: al matar a su padre y cometer incesto con su madre Edipo inicia una nueva cadena causal.

No valen ni las medias tintas epicúreas ni las sofisticaciones modales estoicas: debe defenderse que el sujeto es radicalmente libre, que puede ponerse y realizar sus propios fines más allá de las propensiones naturales. Aunque tendía a ser un borracho y un mujeriego, el filósofo Estilpón dominó y reprimió ese carácter y estos vicios hasta el punto de que "nadie lo vio jamás bebido y nadie vio en él huella de desenfreno». El fisonomista Zópiro, que afirmaba poder conocer el carácter y las costumbres de los individuos observando su constitución física, declaraba que Sócrates tendría que haber sido, en virtud de ésta, un lerdo y un mujeriego, ante lo cual — dice Cicerón- «Alcibíades sufrió un ataque de risa». Ambos ejemplos muestran la primacía de la potestas de la voluntad sobre las causas naturales, que, ciertamente, existen pero que pueden (y deben) ser dirigidas por los actos de voluntad. Aunque los vicios pueden nacer por causas naturales, su eliminación no «depende de causas naturales, sino de la voluntad, del empeño, del aprendizaje» (De fato 10-11). Los romanos, tal vez en mayor medida que los griegos, consideraban humillante ceder ante ese fatum que en tantas ocasiones enmascara la debilidad de la voluntad.

Tras esta maraña de discusión técnica filosófica se esconde, insisto, un problema de profundo significado y sentido religioso, el de si los dioses han decretado desde siempre 
y para siempre nuestro destino, fuente a su vez de temores y supersticiones. Estamos ante un problema religioso que se reinterpreta (o malinterpreta, dígase como se quiera) desde y con categorías filosóficas: la superación de la concepción estoica del fatum, así como de la simétrica y especular azarosidad extrema a la que se ven abocados los epicúreos, exige discernir entre diferentes tipos de causas atendiendo a su relevancia para que se produzcan determinados acontecimientos.

De modo preliminar, en Sobre el destino 20-21, Cicerón distingue entre «causas que preceden por azar» (causae fortuito antegressae) y causas que "albergan en sí mismas una eficiencia de carácter natural» (causae cohibentes in se efficientiam naturales), distinción que se argumenta de manera explícita más adelante, cuando se reconstruyen los argumentos de Carnéades en contra del fatum (Schallenberg, 2008, 205 ss.). Debe precisarse al máximo el concepto de causa. Supongamos la siguiente concatenación de hechos: Nace un árbol en el bosque Pelio $\rightarrow$ Se tala este árbol $\rightarrow$ Con el árbol se construye el Argos $\rightarrow$ Jasón navega con este barco a Colcis $\rightarrow$ En Colcis encuentra a Medea $\rightarrow$ Se desencadena la tragedia. Tal cadena podría retraerse infinitamente al pasado y proyectarse de igual modo al futuro. Es también cierto que, si no se hubiera construido el Argos, no se habría desencadenado la tragedia, pero la construcción del barco no la produce desde sí y por sí: los acontecimientos indicados en la cadena que preceden a la tragedia son sus condiciones necesarias, no suficientes. Sólo el deseo de Medea, su decisión libre y voluntaria de vengarse de Jasón, es causa en el sentido estricto que deberá precisarse a continuación (Stough, 1978, 219).

Un acontecimiento no es causa de otro sólo porque le preceda temporalmente, sino que debe antecederle, dice Cicerón, «de una manera eficiente», efficienter. Entre los muchos acontecimientos que preceden a otro acontecimiento ¿cuál de ellos puede considerarse causa efficiens? El antecedente debe satisfacer dos condiciones: ser condición necesaria y suficiente del consecuente (sine quo effici aliquid non possit y cum quo effici aliquid necesse sit). Cicerón lo matiza con el ejemplo de Filóctetes: no puede decirse que la mordedura de la serpiente causara su abandonado en la isla de Lemnos, esa dentellada no es causa necesaria y suficiente para abandonarlo; debe haber, sin embargo, alguna causa, si bien sólo se descubre más adelante: «Después, sin embargo, se produjo una causa más próxima y más ligada al desenlace». Para establecer la conexión causal (y, por tanto, para asignar responsabilidades) deben tenerse en cuenta las circunstancias concretas del suceso. Por ejemplo: cuando se produjo la picadura los griegos marchaban a Troya y, en esta circunstancia, los doloridos aullidos que profería Filóctetes podrían haber puesto en peligro la misión, de suerte que no hubo más remedio que abandonarlo, aun en contra de los deseos más íntimos. Por eso dice Cicerón: «es al razonar un suceso cuando se descubre cuál es su causa" (ratio igitur eventus aperit causam) (De fato 35-38). Si ahora acudimos al locus paralelo de Tópicos 18, 67 podrá aventurarse que cuando el Arpinate habla de ratio no piensa en una cualidad del sujeto, sino en una relación lógica entre causa efficiens y eventus, sobre cuya base el sujeto puede considerar que un determinado antecedente es causa (ratio eventos). Si se acepta esta interpretación, deberá entonces considerarse que la expresión ratio igitur eventus aperit causam no menta un suceso físico, sino la relación lógica entre un evento y su causa manifiesta (Bernett, 1995, 73-77). Pero esta relación sólo se descubre más adelante. A propósito de los acontecimientos temporalmente alejados respecto de un suceso dado sólo cabe encontrar condiciones necesarias; para dar con la causa en sentido estricto hay que aproximarse al acontecimiento e investigar sus condiciones más próximas: la pregunta por la auténtica causa sólo puede responderse por relación al contexto en el que se produce el acontecimiento que desea investigarse o la responsabilidad que debe atribuirse (Schallenberg, 
2008, 216-217). Tal relativismo está en perfecta consonancia con el escepticismo académico (Magris, 1995).

Pero no debe olvidarse -insisto de nuevo- que aunque el instrumental y las categorías con las que se lleva a cabo la discusión son de carácter lógico-epistemológico, la discusión de fondo no posee tal naturaleza, ya que está en juego un problema religioso, esto es, político-religioso. Siguiendo a Carnéades, Cicerón critica de forma directa la epistemología estoica, pero porque indirectamente, y al margen del filósofo escéptico, desea superar las implicaciones teológicas de la concepción estoica del destino, que toma pie, recordémoslo, en la idea de una enorme cadena causal ininterrumpida y lineal de causas externas cuyos efectos se convierten a su vez en causas de otros efectos posteriores. Crisipo quiso ramificar o desfigurar esta cadena, pero aunque hubiera tenido éxito en su intento no habría sido suficiente, pues de acuerdo con Cicerón hay que romperla por motivos teológicos, o sea, teológico-políticos: para que los malvados puedan ser declarados responsables de sus actos y en consecuencia soporten un castigo divino que, y esto es importante, podrían haber no sufrido caso de haberse conducido de otro modo. No hay que explicar las acciones acudiendo a una larga cadena causal que en último extremo se remonta a los dioses (porque entonces los dioses podrían querer algo malo), sino en virtud de las propias intenciones, en virtud de que el alma es causa de sus acciones: la explicación de sus acciones no requiere ninguna causa externa (a su malvada alma).

¿De dónde proceden los actos o los contenidos concretos de la voluntad? Responde Cicerón: o bien de percepciones de los sentidos o bien de impulsos internos. Respuesta que, a su vez, obliga a preguntar de nuevo ¿en qué medida obran las percepciones y los impulsos un efecto necesario, no sobre la voluntad, sino sobre la formación de la voluntad, esto es, no sobre lo querido, sino sobre el proceso en virtud del cual se quiere lo que se quiere? Cicerón intenta responder a estas difíciles cuestiones sirviéndose del concepto de «asentimiento» (adsensio).

Considerando, no la voluntad en sí misma, sino los procesos que conducen a su formación, Crisipo, en ese difícil equilibrio entre libertad y necesidad al que me refería más arriba, interpreta el asentimiento como eslabón causal entre el objeto de la percepción, la representación (phantasía, visum) y la reacción por parte del sujeto: de aquí el precario equilibrio y, ya lo indicaba, que entre él y los fatalistas sólo haya una diferencia de palabras, pero no en lo esencial, porque Crisipo no acaba de este modo con la rigidez del nexo causal, por lo cual, aunque «se adhiere más bien a los que quieren que los movimientos del espíritu se encuentren liberados de la necesidad» cae en tales dificultades "que corrobora, a su pesar, el carácter del destino» (De fato 39-45). La diferencia entre la solución ciceroniana y la propuesta por Crisipo es, si se quiere, de matiz, pero de consecuencias muy diferentes (Ioppolo, 1998). El Arpinate propone la siguiente secuencia: Representación $\rightarrow$ Impulso irracional $\rightarrow$ Asentimiento $\rightarrow$ Impulso racional (ya que su origen próximo es un asentimiento producto de la mens; cfr. De nat. deor. II, 29) $\rightarrow$ Acción. Crisipo sugería que no se asiente a un impulso, sino a una representación, de suerte que el movimiento del alma es ya, desde sus mismos orígenes, de carácter racional, porque un lógos asiente a algo que es lógos, si bien tal circunstancia sólo la comprende por entero el sabio. Pero la contrapartida de tal racionalidad omniabarcadora es una necesidad no menos omniabarcadora. La coherencia y radicalidad del planteamiento crisipeo es extrema, incluso en exceso para un hombre, Cicerón, cuyos intereses no eran técnicamente filosóficos. Porque Crisipo apunta y a la vez presupone (llevando las palabras a máximos de abstracción mareantes) un Lógos total y absoluto en cuyo seno no es que impere la necesidad más absoluta, es que carecen de sentido esas 
distinciones (v.g. libertad/necesidad) indispensables en el proyecto ciceroniano de reinstrumentalización política de la religión. Porque del planteamiento crisipeo, así como del epicúreo, se sigue que «ni las alabanzas son justas, ni los vituperios, ni las recompensas ni los castigos» (De fat. 39-45), conclusión inaceptable para Cicerón por razones morales y políticas: ¿acaso su glorioso consulado y sus valerosas acciones en el asunto de Catilina pudieron deberse a un raro azar producto de la declinación de los átomos o a una concatenación causal decretada desde siempre? ¿Dónde quedaría entonces la grandeza de su alma?

Pero no es suficiente con esta constatación, debe explicarse además, no qué es la voluntad, sino cómo se forma, esto es, cómo se forma lo querido al margen de la coerción de una determinación externa. Cicerón vuelve a apoyarse en Carnéades, aceptando la distinción lógica entre causas necesarias y suficientes, así como la tesis de que el animus, en la medida en que se mueve a sí mismo, se exterioriza como adsensio y constituye la presuposición para la acción. El primer momento lo constituyen la percepción externa (visa) o el impulso interno (adpetitus): visa y adpetitus son, en el proceso de formación de la voluntad, las causae sine quibus non (De fat. 39-45). Sólo la potestas humana, la capacidad del animus humano para moverse a sí mismo, puede producir la adsensio.

Tanto estoicos como académicos aceptan distinguir entre cosas que están a nuestro arbitrio y cosas que escapan de él. El criterio para diferenciarlas es que haya o no haya posibilidad de intervenir mediante acciones en los acontecimientos (con mayor exactitud: en el proceso de los acontecimientos), de suerte que el acontecer pueda tomar otro curso, esto es, que el lugar de las causas naturales pueda tomarlo un acto subjetivo de la voluntad (Bernett, 1995, 81-82). Por tanto, la relevancia causal de la acción humana consiste en interrumpir, modificar o influir el curso de los acontecimientos externos en el sentido de una realización subjetiva de los fines. Ya lo decía: est aliquid in nostra potestate, «algo» pero no «todo», pues hay dos extremos: de un lado, una causalidad estrictamente necesaria, una sucesión lineal de acontecimientos determinados en una única dirección por causas naturales; de otro, la pura azarosidad de acontecimientos que no suceden según reglas o patrones susceptibles de ser conocidos por los humanos, a no ser tal vez por el sabio. Sólo el sabio es libre, por tanto: nadie es libre, excepto tal vez en la intimidad de su conciencia. Tal fue la experiencia que se hizo durante el principado, la de que nadie es libre o, más bien, la de que cabe libremente hacer cesión de la propia libertad. Felices tiempos aquellos en los que la lógica y la política se daban la mano.

\section{Bibliografía citada}

Bernett, M. (1995): Causarum cognitio. Ciceros Analysen zur politischen Krise der späten römischen Republik, Stuttgart: Franz Steiner.

Duнот, J. J. (1989) : La conception stö̈cienne de la causalité, Paris: Vrin.

KNEALE, W. y M. (1972): El desarrollo de la lógica, Madrid, Tecnos.

Kreter, F. (2006): Kann Fabius bei einer Seeschlacht sterben? Die Geschichte der Logik des Kontingenzproblems von Aristoteles 'De interpretatione 9' bis Cicero 'De fato', Trier: WVT.

Ioppolo, A. M. (1998) : «Le cause antecedenti in Cic. De fato 40 », en J. Barnes, M. Mignucci (eds.), Matters and Metaphysics. Fourth Symposium Hellenisticum, Napoli: Bibliopolis, pp. 397-424.

Long, A. A. y Sedley, D. N. (1990): The Hellenistic Philosophers I. Translations of the principal sources with philosophical commentary, Cambridge: Cambridge University Press.

MAGRIs, A. (1995): «Entwicklungslinien der altgriechischen Schicksalsidee», en Wiener Jahrbuch für Philosophie 27, pp. 79-94 
O'Keefe, T (2005): Epicurus on Freedom, Cambridge: Cambridge University Press.

Rescher, N (1963), «An Interpretation of Aristotle's Doctrine of Future Contigency and Excluded Middle», en Studies in the History of Arabic Logic, Pittsburgh: University of Pittsburgh Press, pp. 43-54.

Schallenberg, M. (2008): Freiheit und Determinismus. Ein philosophischer Kommentar zu Ciceros Schrift «De Fato», Berlin/New York: Walter de Gruyter.

Sedley, D. E. (1992): «Chrysippus on Psychophysical Causality», en M. Nussbaum, J. Brunschwig (eds.), Passions \& Perceptions. Studies in Hellenistic Philosophy of Mind, Cambridge: Cambridge University Press, pp. 313-331.

Stough, Сн. (1978): «Stoic Determinism and Moral Responsability», en J. M. Rist (ed.), The Stoics, Berkeley: University of California Press, pp. 203-231.

Vega ReÑon, L. (1990): La trama de la demostración, Madrid: Alianza Editorial.

Vegetti, M. (1983), «La sagezza dell'attore. Problemi dell'etica stoica», en Aut-aut, 195/196.

Weidemann, H. (2002): Aristoteles. Peri hermeneias (Werke in deutscher Übersetzung. Bd. 1, Teil II. Hrsg. H. Flashar), Berlin, 2002.

Wicke-Reuter, U. (2000): Göttliche Providenz und menschliche Verantwortung bei Ben Sira und in der frühen Stoa, Berlin: Walter de Gruyter.

Facultad de Filosofía

Dept. Filosofía. UNED (Madrid)

SALVADOR MaS

smas@fsof.uned.es

[Artículo aprobado para publicación en noviembre de 2013] 